\title{
The Entrepreneur's Random Walk
}

\author{
Robert Fiore, Springfield College, USA
}

\begin{abstract}
The issues of entrepreneurial ex-ante determination and managerial intent are discussed as applied to the ex-post organizational result. Possible errors in over-attribution of success to the celebrity-entrepreneur and the tendency to disregard the impact of endogenous market conditions, randomness on success due to "creative destruction" free-market mechanisms are discussed.
\end{abstract}

Humans inherently look for correlation as correlations produce useful knowledge. Specifically, investors seek to create cause-effect knowledge in order to enhance returns. Students and researchers of business also attempt to tie causation to effects. Fundamental attribution error psychology posits a tendency to over-weight personality-based explanations and under-value situational factors when assessing what factors are responsible for the ex-post-facto outcome of an organization. In the field of entrepreneurship, this trait of human psychology may manifest in the tendency to credit the leader him/herself of a successful organization vis-a-vis more important external factors which contributed to success such as the temporal status of market demand conditions.

The existence of fundamental attribution error may likewise lead to over-weight emphasis of a leader's input to organizational failure, however, the sample of entrepreneurs linked to successful organizations is self-selected as the unsuccessful entrepreneurs are usually not locatable. Therefore, stakeholders show strong tendencies to link the focus-entrepreneur with a resultant successful enterprise. This tendency is observable in the general culture as most students of entrepreneurship believe the knowledge and actions of "Ray Kroc" were a prime factor in the economic success of McDonald's. The question explored within the present study is to what extent is such ex-post-facto success attributable to the ex-ante entrepreneurial intent appropriate?

Most people familiar with business strongly identify; Steve Jobs with Apple, Thomas Watson with IBM, Dave Thomas with Wendy's, Bill Gates with Microsoft, Howard Schultz with Starbucks, Harland Sanders with KFC, and Fred Smith with FedEX. Instructors of entrepreneurship teach with these stories. More importantly, researchers of entrepreneurship use these leaders and their associated knowledge and behavior as independent variables when regressing these variables onto the ex-post dependent outcome of the organization. The investing and finance community also correlate these "success story" celebrity-entrepreneurs with the resulting rate of return on equity. This paper explores a series of archive-based recollections of the entrepreneur's ex-ante thoughts to demonstrate that many legendary-business entrepreneurs did not expect the organization's extraordinary rates of growth and the ex-post-facto market successes. Hence, cause-effect attribution questions arise.

One important research question addressed within is; if the entrepreneur did not know of, or expect growth before the growth, then the resulting growth may not be fully attributed to the person as valid intent. More generally, then to what extent can the resulting organizational success be attributed to the identified behavior of entrepreneurship? Are the successes normally attributed to individual-entrepreneurs really organizational successes or even randomwalk phenomenon? Are fundamental attribution errors over-weighing the construct of entrepreneurship and obscuring other, organizational-based, effective causes of economic success?

The rise of the media-driven, celebrity-entrepreneur leads to a recent strengthening of attribution of organizational success to that leader. Conclusions within the current study lead to a more distinct focus on the "time-limited" tasks of entrepreneurship that are very limited in proportional impact to a firm's total life-span and resulting economic value. We then can attribute much more of the resulting economic value to the impact of organizational dynamics and organizational development.

Keywords: Entrepreneurship; Management; Small Business Management; Organizational Behavior; Fundamental Attribution Error 


\section{DISCUSSION}

ithin the field of Entrepreneurship, many may believe that a successful organization was started and
stewarded by one identifiable entrepreneur, in spite of a lack of information about important
exogenous factors such as market demand conditions, competitive analysis, economic conditions and the impact of internal organizational teamwork. But was success of one organization due to the creativedestruction or failure of another? Was the successful rise of McDonalds primarily due to the prior or simultaneous failure of many un-identifiable "Burger Queens"? If a strong "Burger Queen" did exist, then McDonalds may have failed, therefore we cannot fully attribute McDonalds' success to "founder" Ray Kroc if we do not attribute such success to a "Burger Queen's" failure.

Humans have a historic and strong tendency to note correlation and infer causation. From ancient times, we tell stories of heroes, in attempt to teach and learn from those stories. A central question in the field of entrepreneurship is; to what extent are the actions of the celebrity-entrepreneurial-hero the actual cause of success and to what extent are the resulting "creation myths" valid and teachable events?

Inc. Magazine, Fast Company, the Wall Street Journal, CNBC and most textbooks of entrepreneurship are replete with interviews with "successful" entrepreneurs. These media sources and many academic journals regularly and strongly identify founders as the creators of the organization and represent them as responsible for the wealth generated. In many minds, Kroc is McDonalds, Schultz is Starbucks, Gates is Microsoft, Dave Thomas is Wendy's, and Jobs is Apple. The basis of management research is to observe and link predecessor events to ex-post outcomes and test causation based on some correlation. The resulting research and the teaching of those results become less valuable if the causal factors are not valid. Hence, it becomes very "troublesome" to imply that the success of any of the companies mentioned above were based on random events and the entrepreneur associated with those companies were not responsible for the finance success often noted.

We imply causation as leaders are given credit for an organization's success. They take credit for a firm's success in public forums to advance the organization. They are expected to have and create optimism and imply causation and managerial-control to obtain funding. Additionally, the media strongly promotes this view of reality as it is necessary for selling the news-article. It is difficult to publish an article that gives credit to thousands of unheard-of names.

It is posited here that the organization itself is the overwhelming cause of success attributed to the entrepreneur. To imply causation with confidence, the entrepreneur would have to consciously have some level of ex-ante knowledge of the ex-post-facto success. To imply causation of ex-post results without ex-ante knowledge implies randomness through the existence of chance events.

Within this paper, the author highlights quotes from well-known entrepreneurs. These men and women are widely associated with their organizations. The organization and its successes are strongly correlated in many people's minds. Within, we can examine ex-ante statements regarding organizational growth and compare them to ex-post growth.

Shane's (2008) research finds that about only $2 \%$ of new firms achieve substantial growth rates and large market capitalizations. Such small success rates may lead to a belief of market-randomness as through millions of creative-destruction start-up events, any one gazelle-like success story may take root as a random-chance event. The question arises, is any one entrepreneurial success determinable? Are high-growth outcomes deterministic? Or, are they the result of a random market-space phenomenon? As a temporary market-space opens, that demand is nearly instantaneously filled with the nearest supply-source and other competing business-plans fail. When compensating for the over-weighting of entrepreneurial success due to attribution-error psychology, factoring in the evidence of archived entrepreneurs statements of ex-ante doubt, and considering the non-repeatability of organizational creation, we may consider successful entrepreneurship a random event in competitive markets.

As an example, Howard Schultz of Starbucks has many times outlined his dream of creating a national brand, his vision of creating a different and more malevolent kind of company. These statements imply causation. 
It should be remembered that the entrepreneur is expected, and at times must, accentuate positive statements in public, as continued successful equity funding is very dependent on perceived signaling of attitude. Ex-post organizational success, the entrepreneur normally is expected to speak and act as if there was deterministic ex-ante knowledge even if there was none.

The issue of actual ex-ante intention-belief of the ex-post organizational growth is questioned. The expost-facto growth is self-evident; the issue of prior knowledge and pre-determination is the issue, as most students attribute Schultz's current statements as casual factors to Starbuck's brand building success. Although Schultz has continuously stated his pre-determined belief-structure, the quote presented below highlights the lack of actual exante knowledge. This extemporaneous and spontaneous statement was recalled by him in 2004 speech at Southern California University as he reflected on his early beliefs.

"I never believed... never... I think it would be arrogant to believe... that we could have 1,000, 2,000, 7,500, stores in the U.S. and around the world."

These extemporaneous statements show a substantial difference between ex-ante, and stated ex-post belief structures. The fact that a chasmatic entrepreneur; claims success, purposely promotes the value of the company, appears confident and in control, appears to have a strong grasp of management and "acts-as-if" there was ex-ante belief and knowledge, should be considered natural as the investors demand such verification before investing. It should also be noted that employees and primary investors promote "leadership-speak" and they encourage the entrepreneur-personality into the media. However, such ex-post public media events should not lead to overt and automatic formulation of belief that the entrepreneur is any more responsible for organizational success than any other person in the firm. Many authors (Hornaday 1990, Dimov 2007, Byers et. al) point out that high-growth entrepreneurship is a collective-social process, and that organizational building is the result of teamwork wherein the entrepreneur personality spends his days in meetings just as any member of management would do.

\section{FUNDAMENTAL ATTRIBUTION ERROR THEORY- THE PHENOMENON OF ATTRIBUTION}

Fundamental attribution error or attribution bias, describes the tendency to over-value dispositional or personality-based explanations for the observed behaviors of others while under-valuing situational explanations for those behaviors. The fundamental attribution error is most visible when people explain the behavior of others. This general tendency is not used to explain interpretations of one's own behavior-where situational factors are often taken into consideration. This discrepancy is called the actor-observer bias.

Ziva (p. 430) describes human tendency to over-identify the impact of a leader's actions with a group's success. She states, “... studies have also demonstrated that we are often too quick to jump to conclusions about others' abilities, traits and attitudes based on small samples of their behavior, we fail to appreciate the extent to which situational forces had contributed to that behavior." Continuing on p. 431, "we simply don't realize how powerful the situation is... we fail to correct our impressions for situational constraints even if we understand these constraints." On page 432, "Our ultimate conclusions about a person may remain contaminated by our initial inferences about this person..." Ziva specifically addresses fundamental attribution error (p. 441), "When we observe or hear about another person's behavior, we often fail to appreciate the extent to which this behavior may have been shaped by circumstances. Instead, we assume that the behavior was driven by the person's enduring underlying disposition."

It is this author's hypothesis that attribution error is a remnant of both cognitive and social evolution, wherein, over a time-frame of eons, human groups survived if they quickly identified and followed any leader, and specifically one they thought exhibited experience. The tendency to quickly identify a leader based on singleattribute assumptions of that leader's abilities was usually based on incomplete dispositional assumptions as a full analysis required to take into account all situational factors would consume more time and energy than the benefit of quicker and simpler assumption. The groups that observed potential leaders based on one good decision (regardless of the external-situational factors that lead to that behavior) survived and natural selection survival outcomes eventually became a genetically-probable cognitive trait. 


\section{THE APPLICATION OF ATTRIBUTION ERROR TO ENTREPRENEURSHIP}

Attribution error may lead both the general public and learned students of entrepreneurship to overemphasize the impact of the celebrity-based entrepreneur's personality on the organization's success. This effect would underemphasize the value of other organizational factors such as team-building, hiring talented people, brainstorming, and group dynamics. Errors of mis-identification leads research results to inappropriate conclusions.

It is acknowledged that the initial development of organization is crucial in producing economic value, and that the resulting growth could not have occurred without the acts of creation. But the resulting organizationalgrowth was dependent on the work, synergy and talents of the people within the organization. The final form of the organization reflects with current market needs and is the result of endless market-adaptation not the ex-ante deterministic knowledge of the entrepreneur. In the case of McDonalds, founder Ray Kroc did not invent the FishFilet, the Big-Mac, or the Breakfast menu, the franchisee-organization created these product-lines, and Harry Sonoborn created the critically important real-estate buy and lease-back scheme, henceforth, Kroc cannot be given direct causation credit.

\section{BUT WHAT IF:}

Students sometimes ask, if I study and re-create Ray Kroc's behaviors, actions and skills, and I do exactly today what Kroc did on a day-by-day basis... then would I create another organization equal to the value of McDonalds? Although the question seems naive, the answer has an important result. The answer is probably no. Successful organizations are non-repeatable. Even Kroc could not presently re-create another McDonalds. We conclude that the present externalities are different than those as existed in 1950-1980, hence the success of Kroc was dependent on the then existing external conditions. Hence, externalities are of crucial importance even for entrepreneurial firms. The competitive forces fostering constantly changing market conditions promote creative destruction action leading us to the conclusion that randomness is a strong component in entrepreneurial success.

Furthermore, the sequence of events would have to be re-created to copy success. For McDonalds to be a "success" many events had to occur, in a particular sequence, within the firms in relation to the external market and economic environment. This event-sequencing and internal-external relationship cannot be re-created.

For example, McDonalds' success was likely dependent on the occurrence of the following events:

The existence of the McDonalds brothers assembly-line approach + McDonalds brothers not themselves wishing to expand + Kroc's Multi-Mixer equipment restaurant experience + the McDonald brothers desire to sell the firm + Kroc actually buying the brothers out + Kroc's ability to obtain financing + favorable market conditions for hamburger + the McDonald brothers cognition of assembly-line manufacturing to service + favorable external economic conditions + growth in population + growth in the number of automobiles + cheap transportation costs + failure of competitions + successful stock IPO + creation of franchise concept + creation of franchisee real estate lease-rent contracts + hiring Harry Sonoborn + timely acquisition of real estate + talent in real estate acquisition + creative product development input by franchisees + cheap beef prices + agreements with the Simplot company to supply potatoes + the existence of mega-farms $+\ldots$

We may conclude that so many internal and external events had to transpire and so many more situational factors vis-a-vis Kroc's personal factors had to be in place, that the economic success of the organization in total, mimics random events. Since a successful organizational outcome cannot be "re-created" by "re-enacting" a founder's exact behavior, we may conclude that situational factors are more important than dispositional factors.

\section{THE ENTREPRENEUR'S OWN WORDS AND ANALYSIS:}

The following are spontaneous quotes, found ex-post success from video archives featuring some important entrepreneurs. 


\section{Dave Thomas (Founder, Wendy's)}

"I thought my big deal in life had been KFC, Kentucky Fried Chicken, when I sold out to the company, and become a millionaire, I thought that was, you know, I wasn't ever going to strike anything that big, or, but I was wrong."

This quote was recorded well after David sold his interest in KFC. This extemporaneous insight seems to be Thomas's best recollection of his actual state-of-mind and belief structure prior to the starting of the first Wendy's in 1969. The quote helps demonstrate that even though the company subsequently came to a multiple-billion dollar capitalization, he had little or no ex-ante expectation or managerial-intention that the firm would be as successful as it eventually was. Hence, we may conclude that although most observers attribute assumed intentionalentrepreneurial foresight due to ex-post-facto success, such attribution may be an error. We may conclude that environmental market-environment, teamwork, and managerial talent hired other than Dave's had a proportionally much greater impact on the resulting value of the organization viv-a-vis the initial entrepreneurial tasks.

\section{Ray Kroc (Founder, McDonalds)}

Here, CNBC interviewer Carl Quintanilla interviews Al Golin, the public relations vice president as a proxy for the late Ray Kroc.

Carl Quintanilla speaking; “In 1957 Al Golin became McDonald's first P.R. man... He's still doing it a half century later. He (Kroc) talked a lot about getting big, having a thousand stores, for instance. Do you think he actually believed it was going to happen?"

Al Golin; “No, I don't think so... because when I would sit with him, in an interview... in the early days... and a reporter would ask him, well, how many of these (stores) can you really open Ray? And, he'd say, we're going to open a thousand someday... then we'd go outside... and he'd give me a little wink, and say, yeah... that'll be the day."

This insight is from a close and longtime work colleague of Kroc's who knew him personally. The McDonalds enterprise currently has a market value of about $\$ 100$ billion dollars. The central question is, did Kroc possess exante entrepreneurial expectations, and knowledge of such growth? Did he pre-see the outcome or was the success an accident? As most students of entrepreneurship attribute the success of McDonalds with the abilities of Kroc, if Kroc did not demonstrate the intention of this level of growth and showed little ex-ante belief and expectations of such outcome, can we attribute ex-post success with him? Golin's recollection clearly demonstrates that Kroc was ignorant of intentional outcome. Therefore, the attribution of Kroc's ex-ante knowledge or talent as a primary factor in the ex-post success of the McDonald's organization is not valid.

\section{Ray Kroc (Founder, McDonalds)}

Another video archive provides insight to the effectiveness of Kroc in relation to the overall success of McDonalds. John Love, author of Big Mac: Inside the McDonald's Empire provides insight that Kroc may have failed unless his Vice President, Harry Sonoborn provided the innovation necessary to engender growth.

John Love speaking; “... unfortunately (Kroc) basically gave (the McDonald brothers) a deal on which (Kroc) could not make any money... until he met Harry Sonoborn, who showed him how to make money, not on selling hamburgers, but real estate... the concept of renting real estate to franchisees was absolute critical to the success of McDonalds in every respect."

If the actual success of McDonalds was actually due to the knowledge input of Sonoborn, then the attribution of success to Kroc is in error. 
4. Howard Schultz (Founder, Starbucks)

Howard Schultz spoke at USC in 1994,

Schultz speaking; "I never believed, dream of, never... I think it would be arrogant to believe, that we could have $1,000,2,000$, or 7,500 stores in the U.S. and around the world."

As discussed, in his biographies and current spaces, Schultz regularly infers ex-ante determination. He promotes the idea that he did possess the vision that became Starbucks. The quote highlighted above indicates that he did not possess ex-ante knowledge of the extent of resulting success and therefore the majority of the resulting success cannot be attributed to the possession of a set of ex-ante, entrepreneurial, innate, and intentional knowledge.

5. Ben \& Jerry (Ben \& Jerry's)

Ben Cohen: "We didn't have much to lose, we had nothing."

Jerry Greenfield: "It was something to do, it was an adventure, it was a project."

Ben Cohen: "We thought it was a big risk, in that nine out of ten businesses fail... and why shouldn't we?"

Again, this quote demonstrates no pre-determinate vision of growth, no identification of competitive advantage in a market, and little or no ex-ante knowledge of the resulting market-impact or economic large capitalization.

This quote supports the proposal that the primary entrepreneurs of many organizations that subsequently grew to large capitalizations had little or no prior ex-ante conception of the amount of growth, market size or the extent of competitive advantage useful in capturing the eventual market size. This raises the proposition that in a fully competitive economic market, the winners are largely a result of randomness, and that causation of a "special or entrepreneurial" knowledge set, is invalid.

\section{Sky Dayton (Founder, EarthLink)}

"I wrote a business plan, for me it was quite an opus... it was ten pages... had a few graphs in it. It called for breakeven at 600 customers. It called for scaling up to adding 30 customers a week, which would be big. In contrast, EarthLink adds about 30 customers a minute."

Mr. Dayton's quote shows a lack of ex-ante knowledge of the market or opportunity.

7. Roxanne Quimby, (Co-Founder, Bert's Bees)

"Sometimes, the most inventive ideas come out of accidents, serendipity... who knows where they come from, they kind of fly in, and, well, let's try that..."

Ms. Quimby's quote acknowledges her thought of the randomness of the events that lead to the creation of a firm eventually being bought for more than $\$ 400$ million dollars.

\section{CONCLUSIONS}

The constructs of market opportunity definition, start-up intent, start-up planning, mission development, feasibility analysis, acquisition of resources, define the stage of entrepreneurship. Although critical, this characteristic stage of organizational development lasts a short period of time. These functions of entrepreneurship are a valid construct, and the general public often identified one person as responsible for initiation of this event. Attribution Error may induce people to over-identify the cases of organizational growth within later stages, with the initial entrepreneur, therefore undervaluing many later-stage organizational growth factors. 
The later-stage organizational growth and wealth generated may be largely due to nominal managerial organizational development, wherein the staff and management are responsible for the large share of wealth generation and rate of returns to investors.

The success of any one new organization may even be considered to be a random-chance event wherein the market acceptance of the new company depends on market acceptance and open-market-space is temporal in nature. Furthermore, entrepreneurial actions leading to success are non-repeatable, indicating randomness to success. Market acceptance is dependent on a large number of critical factors all necessary for growth. The numbers of possible factors necessary for economic success and growth into a capitalize-able venture that the success of new nascent organizations may be considered a random event.

It is posed within that most entrepreneurs are not cognizant of growth/success potential and that the growth and market value created are not conscience intents. Therefore, attribution cannot be directly ascribed to the skills and ex-ante knowledge of the entrepreneur. This leads to the conclusion of a large factor of randomness to firms with large capitalizations and resultant rates of return may be random events.

Entrepreneurial tasks are well specified. The initial tasks of capital accumulation, labor-retention, initial organizational set-up, the formulation of mission and values, culture initiation, product innovation and development, and delivery systems are well specified. Yet these initial tasks are accomplished in a brief period, usually lasting less than $1 \%$ of an organization's lifespan. The person identified with providing leadership in this period may not be responsible for the remaining $99 \%$ of the organization's life wherein the majority of product-line refinement, market expansion, revenue enhancement and value-creation are accomplished.

We may conclude that the entrepreneurial tasks are of most importance but the time-duration and resultant growth are much more important even though they are sequence dependent of the initial creation-act. In reverse, the initial-creation tasks are resultant in the vast majority of the remaining tasks and the value-creation during subsequent organizational development.

\section{AUTHOR INFORMATION}

Dr. Robert Fiore is Professor of Business Administration at Springfield College, Springfield, MA USA. E-mail: rfiore@spfldcol.edu

\section{REFERENCES}

1. Byers, T., Kist, Helen, Sutton, R., Characteristics of the Entrepreneur: Social Creatures, Not Solo Heroes, Paper Prepared for The Handbook of Technology Management, Richard C. Dorf (Editor), CRC Press LLC., Boca Raton, FL, 33431.

2. $\quad$ Bygrave, W.D., Fast, N., Khoylian, R., Vincent, L., 1989, Early Rates of Return on 131 Venture Capital Firms started 1978-1984, Journal of Business Venturing, Vol. 4, p. 93-106.

3. Dimov, D., 2007, Beyond the Single-Person, Single-Insight Attribution in Understanding Entrepreneurial Opportunities, Entrepreneurship: Theory and Practice.

4. Gompers, P., Kovner, A., Lerner, J., Scharfstein, D., Oct. 2006, Skill vs. Luck in Entrepreneurship and Venture Capital: Evidence from Serial Entrepreneurs, NBER Working Papers, Working Paper 12592, http://www.nber.org/papers/w12592, National Bureau of Economic Research.

5. Jones, E.E., Harris, V.A., 1967, The Attribution of Attitudes, Journal of Experimental Social Psychology, $3,(1)$, p. $1-24$.

6. Love, J., (1986) McDonalds, Behind the Arches, Bantam Books.

7. Hornaday, R., 1990, Dropping the E-Words from Small Business Research: An Alternative Typology, Journal of Small Business Management, 28, 4, p. 22-33.

8. Palich, L., Bagby, D.R., 1999, Using Cognitive Theory to Explain Entrepreneurial Risk-Taking: Challenging Conventional Wisdom, Journal of Business Venturing, Vol. 10, issue 6, p. 425-438. 
9. $\quad$ Rogoff, E.G., M. Lee, D. Suh, October 2004, "Who Done It?": Attributions by Entrepreneurs and Experts of the Factors That Cause and Impede Small Business Success", Journal of Small Business Management, Vol. 42, Issue 4, p. 364-376.

10. Shane, S. (2008), The Illusions of Entrepreneurship, Yale Press.

11. Ziva, K., 1999, Social Cognition: Making Sense of People, Massachusetts Institute of Technology.

\section{Video Archive Sources}

1. Dave Thomas, Made to Order, VHS, Biography, Cat. No. AAE-17295, 1998 A\&E Televisions Networks, New Video Group, 126 Fifth Avenue, New York, N.Y. 10011.

2. Big Mac: Inside the McDonald's Empire, CNBC Original Production, October, 2009. ASIN B002SF9Y7U.

3. Ray Kroc, Fast Food McMillionaire, VHS, Biography, Cat. No. AAE-17293, 1998 A\&E Televisions Networks, New Video Group, 126 Fifth Avenue, New York, N.Y. 10011.

4. Howard Schultz, Chairman and Chief Global Strategist, Starbucks Coffee Company, 2004 Entrepreneur of the Year, DVD, Lloyd Greif Center for Entrepreneurial Studies, USC Marshal School of Business, Los Angeles, CA 90089.

5. Ben \& Jerry, Biography on $C N B C$, Season 1, Episode 4. A\&E Television Networks, 2005.

6. Sky Dayton, Founder, EarthLink, 1999 Entrepreneur of the Year, USC Marshall School of Business, Greif Entrepreneur Center, VHS, www.Marshall.USC.edu/entrepruer.

7. CNBC Video, Jan 9, 2008, Roxanne Quimby, Bert's Bees, How I made My Millions, David Faber, The Maine Idea. 